\title{
Police Psychologists as Expert Witnesses in Appeal Hearings: Testimony for Disqualified Applicants and Fitness-for-Duty Forensic Psychological Evaluations
}

Ronn Johnson *

University of San Diego, School, Family, Mental Health Professions, California, USA

*Corresponding author: Ronn Johnson, Ph. D., ABPP, University of San Diego, 3525 Del Mar Heights Road \#302, San Diego, CA. 92130, USA, E-mail: ronnjohn@sandiego.edu

Rec date: Dec 22, 2014 Acc date: Jan 20, 2015 Pub date: Jan 25, 2015

Copyright: (c) 2015 Johnson R. This is an open-access article distributed under the terms of the Creative Commons Attribution License, which permits unrestricted use, distribution, and reproduction in any medium, provided the original author and source are credited.

\begin{abstract}
The Boston Marathon Bombing is a terrorizing international reminder of the intertwined domestic and Homeland Security scene management demands confronted by police officers. Protests following the death of three black males indicate that police must exercise integrity and maintain public trust despite boundary intrusions from their surging personal life stressors. The post-Ferguson psychological screening, training, retention, and supervision of police officers are nonetheless challenging. The Boston Marathon Bombings, Homeland Security issues and Ferguson, Missouri incident all point to the relevance that psychological evaluations play as a critical tool in shaping how departments make decisions about applicants and incumbent officers. Police departments have mandated psychological evaluations for applicants and have implemented fitness-for-duty triggering mechanisms for those desiring to remain police officers after some perceived misconduct. Litigation alleging negligent hire or retention factors tends to reinforce the need for a suitability operational standard of "rule out" for police psychological evaluations. The decisions from these evaluations lead to appeal situations as individuals may disagree with what they view as unfavorable psychological findings and recommendations. This article examines forensic issues related to the appeal process, with considerable attention devoted to preparation factors associated with a psychologist's sworn testimony often provided at appellant hearings.
\end{abstract}

Keywords: Fitness-for-duty; Forensic evaluations; Mandated evaluations

\section{Introduction}

Domestic disturbances, racially charged misconduct allegations, single shooter incidents, traffic, and terrorism are some of the anticipated scene management situations confronting police officers in the 21st Century [1]. For example, the Boston Marathon Bombing was a terrorizing international reminder of the intertwined domestic and Homeland Security scene management demands police officers are exposed to during their work. At the same time, there were peaceful protests in the United States following the death of three black males by police. There were actually looting incidents and riots after the first death that took place in Ferguson, Missouri in the United States. These incidents drove home the suitability point that police officers must be able to exercise integrity and maintain ethnoracial trust despite boundary intrusions from their own surging personal life stressors. The post-Ferguson psychological screening, training, retention, and supervision of police officers are nonetheless challenging.

Identified as the most stressful careers, the police work places vacillating vigilance demands on to police officers, which can compromise the job performances [1]. Resilient psychological filters are critical to withstand unrelenting stress [2]. Many police departments have mandated psychological evaluations for all those seeking to become or remain police officers, in an effort to exclude those individuals suspected of having problematic behaviors (i.e., on or off duty misconduct) according to Corey and Honig [3]. For example, a police officer was arrested after shooting another motorist in an off-duty road rage incident. Officers are expected to exercise proper judgment on and off-duty. This incident raised considerable concern about the officer's suitability and decision making. Another judgment situation involved an incident whereby within two seconds after arriving on the scene, a Cleveland Police officer in the United States shot and killed a 12-year black male. The child was observed brandishing a toy gun. The same officer involved in the above shooting had previously resigned a police officer position with another department in lieu of termination in lieu of termination. In this case, his prior job performance evaluations from the old police department raised serious questions about the judgment of the officer, particularly in use of force situations (i.e., shootings). Somehow this information was either ignored or not secured in advance of him being hired by the Cleveland Policed Department where he worked at the time of the aforementioned shooting.

The anticipated litigation stemming from cases like these are expected to be at least partly based on negligent hire or retention issues. As a result, the psychological evaluation process, or lack thereof, by default becomes a primary source for critical review. The psychological evaluation process performed by qualified examiners is guided by codes, laws, standards of practice, and/or department policy. The psychological evaluation program (i.e., risk assessment for suitability and ethnoracial risk assessment) is intended to identify applicants or unfit incumbents that are expected to more likely than not pose a great risk to the department for misconduct, or could create unwanted erosion of ethnoracial public trust [4-8]. Litigation based on negligent hire and retention functions as an economic driving force as to why "rule out" is the operating standard of culturally responsive practice in this evaluation area of police psychology [8].

A pre-employment psychological evaluation (PEPE) for an armed peace officer position involves assessing applicants for emotional 
stability and suitability. All applicants are screened for issues that may put them at a greater risk for unwanted reactions to the demands associated with the job of police officer [9]. The International Association of Chiefs of Police (IACP 2009) has established guidelines for these types of psychological evaluations. Psychological screenings are also typical for transfer and special unit assignments.

The IACP also has guidelines for fitness-for-duty psychological evaluations (FFDE) (IACP 2009). The FFDE triggering mechanism usually occurs after an authoritative report to the command that an officer is displaying symptoms of poor judgment, mental illness, or mental impairment in the workplace is the most common precursor to an FFDE. Poor work relationships in diverse settings are another trigger for these evaluations. The article examines forensic issues related to the police applicant or fitness for duty appeal process, including ethics, expert competence for sworn testimony, second opinions, and preventing negligent hires. Implications for culturally responsive practice, research, and training are highlighted. Cumulative stress can lead to an officer making preventable misjudgments that result in undesirable behavioral consequences (e.g., harm to others or erosion of public trust) [10-13]. For example, a police applicant with financial stress may be vulnerable to bribes or theft. Or, someone arrested for soliciting prostitutes may have trouble establishing testimony credibility in court cases where they are testifying. An applicant who made threatening phone calls to a romantic competitor may be unstable when assigned to work with their police partners. The disqualification (DQ) or unfit designation for an applicant or incumbent officer does not have to meet diagnostic criteria from the DSM-5 or ICD-10. These examinees are individuals often present as normal and reasonable people when they are on the police evaluation stage.

Yet, problematic areas are often reflected in the history, psychological interview behavior, personal records, psychological testing, thinking, reasoning, or interactions with the department during processing [14].

Police departments and the communities they serve are diverse cultures within cultures that must have officers that can be assessed as being suitable for consistently operating in ways that are relatively free of corruption, discrimination, rudeness, poor judgment, no potential markers for malfeasance, racial bias, or signs pointing to possible forms of abuse while exercising their authority [15]. Anti-Semitism, Islamophobia, and other discrimination based on gender, LGBTQTIA status, and other ethnoracial characteristics can also point to troublesome appellant issues [16-18]. It is important to assess how an officer perceives personal corruption in order to identify those individuals who are more vulnerable to breaches or misconduct. An appellant's reasoning, or the way he/she describes problematic or questionable judgment may be sufficient grounds for meeting a "rule out" behavioral criteria. Integrity Personal Corruption (IPC), which refers to any behavior that reflects a potentially a problematic break or unwanted deviation from a desired life course, is not always criminal but can nonetheless result in suitability issues for an evaluated appellant [19].

Most departments allow disqualified candidates or officers designated as unfit to challenge the findings, through a Psychological Appeal Hearing $(\mathrm{PAH})$ process. Usually appellants may secure, at their own expense, an approved and qualified psychological examiner who would conduct an outside evaluation and then craft an Outside Examination (OE) report. The examiners must be supplied full copies of all the data relied upon by previous examiners including the full version of prior psychological reports. PEPE and FFDE are often the first documents requested by attorneys during police litigation. Effective evaluations can reduce this legal exposure, as well as reduce misconduct incidents, and result in more trusting relationships with the public.

Some contract examiners may erroneously assume that since they are not directly working for the department they are somehow exempt from being charged with ethical breaches or malpractice stemming from their psychological reports or appeal hearing testimony. This observation is particularly relevant for OE opinion doctors who offer opinions with little or no professional self-filtering as to whether their responses to hearing questions are consistent with their documented competencies, such as APA-approved training and qualified supervision for all their police psychology work [20,21].

The vast majority of police officers are well-trained and professional. However misconduct, paired with the possibility of more negative exposure through smart-phone video recordings can erode public trust and increase litigation [22,23]. Departments can reduce their liability for multi-million dollar out-of-court settlements, through better psychological evaluation systems.

Often, the appellant may secure a legal representative or present their own countering case-relevant information at the appeal hearing. Some jurisdictions have a standing committee authorized to hear such cases. Many hearings involve sworn testimony by the psychologists who have authored the various evaluation reports.

\section{Science of Psychology, Assessing Competence and Ethics Nexus}

Ethically appropriate police psychology practice assumes an important evaluation role in hiring, preparation, and supervision of police officers [24]. The science of psychology is defined as the integration of the best available research with expertise in the context of one of the police psychology and public safety domains (ABPP, 2012). Both pragmatically and ethically, police psychologists should apply the fundamentals of psychological science to their work $[25,26]$. This practice also implies that a psychologist working in police domains must be assessed as being aligned as a scientist-practitioner as opposed to a practitioner [27]. A practitioner is licensed and trained but may not meet the criteria for being a scientist-practitioner because of failure to contribute to the knowledge base in a peer-reviewed or substantial way. Some practitioners' training may be dated or circumscribed to areas not germane to the police psychological evaluations being conducted. They may also fail to remain actively involved or informed through relevant APA-approved trainings in police psychology beyond generic minimum licensure renewal CEU requirements reveals striking contrasts between practitioners and scientist practitioners provide considerable evidence of a scientistpractitioner competence gap $[27,28]$.

According to Principle 2.01 of the APA Ethics Code, psychologists should only provide services "within the boundaries of their competence, based on education, training, supervised experience, consultation, study or personal experience" (p. 5). If they plan to work within this new area, they must obtain the necessary training, consultation, or supervised experience [20]. Consistent with the aforementioned codes, a psychologist has five ethical obligations to citizens, department, hearing officers, and the appellant: reasonable behavior, truth, competence, science-based practice and nonmalfeasance. Standards of practice are established on police 
psychology demands including professional codes of ethics, case law, state and federal laws, existing best practices. (e.g., IACP, POST, current police psychology literature), and widely endorsed professional practice guidelines [29].

Psychologists on both sides of the appellant hearing must also recognize that an opinion could subsequently result in malfeasance and malpractice vulnerability [30]. The malpractice risks for police psychologists generally arise from two directions: 1) improperly or unethically offering hearing testimony or psychological report opinion or recommendation that is beyond the scope of their practice competence. 2) Improperly assessing by failing to flag a behavioral disorder (i.e., glossing over issues) of an applicant or incumbent officer that is recommended as fit or suitable for hire. Though a psychologist risks liability from either direction, ethical practice does offer some malpractice protection (e.g., empirical justification of methods used) for examiners [31].

Ethical principles enable psychologists to interpret each specific situation [32]. Safe ethical practice means that a psychologist must engage in a two-step ethical audit. The first step identifies underlying motives and potential role conflicts that may compromise (i.e., distort ethical reasoning capabilities) professional judgment [33]. The examiner must refrain from anything that might impact the accuracy and objectivity of work [34]. The second ethical audit step is to periodically have a qualified two independent colleagues review key aspects of the psychologist's work to identify a framework where potential ethical threats may arise, then highlight measures that may be taken as defensible safeguards.

\section{Ethics and Science of Psychology Connection}

A psychologist contributing to the refereed knowledge base is directly related to the science of psychology; such demonstrated competence in the services provided serves as an important ethical strategy for the practitioner [35]. The emphasis on competence assessment has been a part of psychology for several decades. Competence in this context refers to the capacity to perform the full scope of tasks associated with police psychological evaluations (i.e., beyond the evaluation proper). The National Advisory Commission on Criminal Justice Standards and Goals reinforced the imperative of using a competent psychologist (1973).

Connection to the science of psychology is a more rigorous standard than "practitioner", requiring assessment for competencies required for testimony in appellant hearings [36]. An assessment of a psychological connection to the science for appellant hearings must be based on an assessment tool, which differentiates practitioners from scientist-practitioners for the purposes of a Daubert Analysis of the expert. Figure 1 provides a schema of an assessment to measure a police psychologist's connection to the science of psychology, in order to assign weight to his/her testimony.

As illustrated in Figure 1, the rating scale could be adapted to use for assessing competency in a number of practice areas. The assessment can be done by the psychologist him/herself or by qualified professionals. Testimonials or years of private practice experience are not sufficient for establishing a connection to the science of psychology.

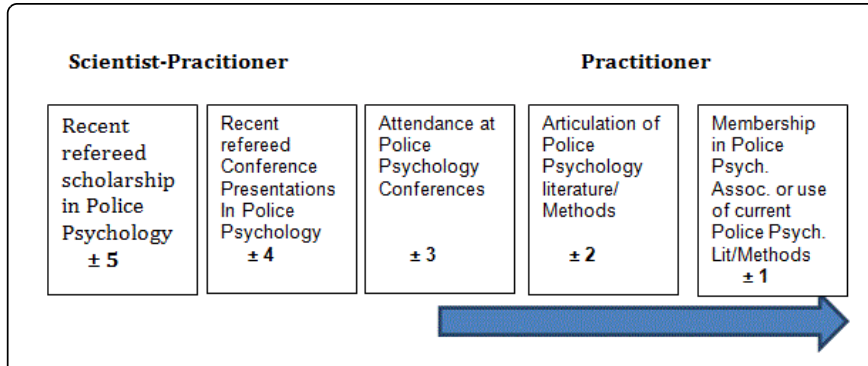

Figure 1: Rating scale for assessment of connections to the science of psychology

For police psychological evaluations, the rating scale must be used with attention to recency (e.g., within the last two years) and substantiality (e.g., at least two peer-reviewed items to receive the positive numerical value attached to the specific domain). The scale is both additive and subtractive. In other words, a psychologist lacking an element would have a number subtracted from each applicable domain. For example, a psychologist who has no scholarship (e.g., in the last two years) would have that number (e.g., 5) subtracted and receives a -5 for that domain. The same psychologist might receive a +3 for attendance at a 14-hour police psychology CEU workshop. Simply attending CEU workshops over the years is not considered sufficient for this assessment or equivalent to graduate-level training. The evaluation methods of attendees at workshops lack academic rigor for those passively participating. Figure 2 is an example of the Science of Psychology rating profile of the five domains for a hypothetical Dr. W.

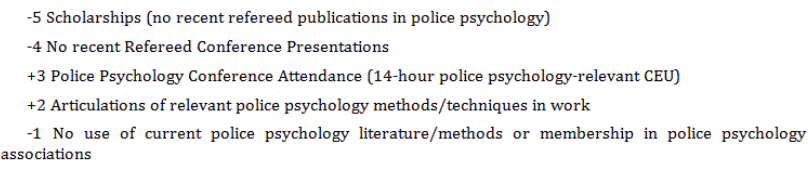

Figure 2: Rating connections to the science of psychology domain for Dr. W.

There is a difference between a practitioner's subjective and dated knowledge versus knowledge based on the science of psychology. As a result, practitioners have limits to their practice scope. Some psychologists fall short due to self-deceiving confidence of what they mistakenly believe, are the facts in a particular psychological evaluation. The psychologist must be aware of relevant laws and policies pertaining to the cases they evaluate, with continuous sensitivity to risk assessment [37].

Another method that may be used to judge competency (i.e., testimonials of years of private practice and competency self-audit) is somewhat limited when compared to the aforementioned approach. For example, there are a paucity of psychologists who devote the bulk of their practice, research and supervision to performing this type of work. No investigations were found that examined the perceptions of psychologists as to whether or not they functioned under any special ethical codes or practice guides that exhorted them to possess specific competence with respect to the issues presented by these type of cases. Forensically relevant psychological standards (e.g., Federal Rule of Evidence 702-705, Frye and Daubert Standards) may offer much 
needed guidance for assessing whether or not someone working with these cases is actually qualified by reason of their knowledge, skill, experience, refereed scholarly work, training, or education in a field of specialized knowledge [38].

Both the dearth of forensic research and the relative absence of documentable expertise with police evaluations work serve to reinforce a need for adherence to guidelines found in the APA Ethical Codes and Forensic psychology guidelines codes. That is, psychologists are ethically obligated to ensure their own competence for working with police work. The problem with this recommendation is on a whole people are often inaccurate in their self-assessments of any characteristic or competency. Since these evaluations are not usually a primary area of expertise for many psychologists, by default it carries with it an extra burden for a psychologist to exercise scientific responsibility (i.e., understanding the applied clinical forensic science). Too often, competence in working with these evaluations can be confused with how much general education or training one has received in the distant past, instead of how much targeted experience or specific training can be documented recently that they have been learned and able to demonstrate through effective forensic work [39].

Complicating this ethical dilemma even further, the lens through which we view ourselves may result in an inaccurate self-assessment of competence. A distorted cognitive schema here contributes to an even greater challenge due at least in part to an inability to accurately calculate the potential adverse malpractice risk consequences stemming from police work (e.g., faulty manner of applying informed ethical thinking to our decision-making in practice). The shortcomings discussed above, lend support for the recommended quantitative metrics included in Figure 1.

\section{Overview of Psychological Appeal Hearings (PAH)}

Appellant hearings for psychological disqualifications (DQs) are based on the administrative or procedural role of the law [40,41]. Appellants are sometimes allowed to have witnesses testify on their behalf. At issue is whether the process and information contained in the psychological report more likely than not warrants the appellant receiving a designation of no pass, bypass, not suitable or unfit [42]. For the psychologist working for the department, the policies or professional standards allow for challenge to their findings and recommendations vis-à-vis an OE report or as part of the appeal.

The decision on whether to disqualify is based on the psychological evidence presented by the department and the appellant. Towards this end, it is essential that hearing officers have a documented psychological training background sufficient for understanding the relationships between the strengths and weaknesses of complex PAH factors (i.e., reports and limits of opinions). Years of experience hearing cases are insufficient to document competence of hearing officers.

\section{Assessing the Role and Responsibilities of Experts and Standards of Practice}

Psychological experts work to inform the trier of fact about variables beyond its expertise [43]. The psychological examiner, through report, consultation, and testimony must apply psychological science to questions relative to the appellant's psychological evaluation. Experts also need knowledge, ongoing ethnoracial competence, training, and experience with the role of a forensic examiner.

Many PAHs consider reviewing three psychological reports (e.g., two from the department and one from the appellant). The standard of practice dictates that each report must be based on the same psychological testing data, independent psychological interview, and all previous psychological reports. Another standard of practice prohibits conditional statements or qualifiers connected to the suitability rating (e.g., "depending on", "may be found suitable" or other hedging statements) in the psychological report, which do not provide the deniability or liability cushion that the psychological evaluator may hope for with regards to their report recommendations.

An examiner must firmly and unequivocally state their final opinion on the appellant regarding their suitability or lack thereof. The first opinion (from the department) on an appellant can prompt a department to request a second evaluation opinion. Some departments do not pay for second opinions if an applicant is disqualified, but do allow appellants to secure their own outside evaluation opinions, with certain stipulations regarding the qualifications and use of previous records. Other departments, per policy, send all disqualified appellants for a second opinion, to extend an appellant the benefit of the doubt. Or, a department can make an in-house second opinion request because of concerns raised during the first opinion evaluation. Although all recent (e.g., within one year) psychological evaluations associated with a particular case are relevant, the PAH usually focuses on the OE report (appellant's psychologist) and the department's psychological reports (first and second opinion reports).

\section{Second Opinion Psychological Evaluations of Appellants}

The appellant's narrative is examined along with psychological testing, documents from the department, and the previous psychological reports. Intentional or unwitting untruths are always possible when conducting these types of evaluations. The second opinion evaluation cannot presume the veracity of any appellant's statement. The examiner must operate with the Four Cs of second opinion evaluations: Clarify (findings of all previous examiners), Change (impressions left from the previous reports), Challenge (findings, opinions, and recommendations), and Confirm (identify points of agreement) information that leads to an independent final recommendation [14].

The examiner of the second opinion report has an ethical and professional obligation to address the issues and opinions raised in the first opinion evaluation. The $\mathrm{OE}$ and second opinion examiners must provide a sound rationale for their agreement or disagreement with the findings and opinions of previous reports, based on the science of psychology. The second opinion is directed toward identifying an appellant's integrity personal corruption (IPC), so as to identify those who are more vulnerable to breaches or misconduct that lead to charges of negligent hire or retention. An appellant's thinking and reasoning, or the way he/she describes problematic or questionable judgment are sufficient grounds for "rule out" behavioral disqualification. The following list of second opinion guidelines can assist in identifying an appellant's integrity personal corruption. 


\section{Keys to Second Opinion Evaluation Decision-Making}

- Perform an evaluation that analyzes issues central to the first opinion evaluation.

- Craft a strong plan for conducting the second opinion psychological interview.

- Resolve questions or unresolved details from the first opinion psychological interview.

- Perform a second opinion analysis of raw data to determine if alternative or new issues emerge, and note any inconsistencies reported by the appellant.

- Set the stage for crafting a defensible second opinion report.

- Understand the facts and circumstances specifically related to the job-relevant demands.

\section{Outside Evaluations (OE report) of Appellants}

The OE report written by a psychologist hired by the appellant, recommends (e.g., Pass or Suitable) him/her for a sworn weaponcarrying position. The ethical, malpractice, and professional challenges for the OE psychologists are three-fold. First, the OE report must provide a psychologically-sound and defensible rationale for overriding what may be two previous psychological evaluation opinions which determined that the appellant is unfit for duty [44]. Second, the OE report must provide a detailed and strong counterarguments (i.e., beyond "I disagree" etc.) to each of the disqualification (DQ) issues identified in previous reports.

The OE report loses credibility if words are parsed, previous disqualifying data is summarily dismissed without sufficient countering data, or, an OE report has reasoned around problematic disclosures or other negative information available at the time of an OE interview. Finally, a weak or lopsided opinion in the OE Report may not establish enough scientific credibility to mute the charge of bias. In the book, Whores of the Court, Margaret Hagen discusses the proclivity for some experts to agree to render any opinion as long as they are paid to do so [14].

\section{Cross Examination by Attorneys in Psychological Appellant Hearings}

Psychologists must testify as to how their psychological methods and procedures resulted in their findings and opinions regarding a particular appellant [45]. This process requires the expert to persuasively describe facts and opinions in a way that can be understood by hearing officers. Some practitioner's current connection to the science of psychology may be weak inadequate and practice unethically within the context of the PAH. Therefore, psychologists preparing for PAH must conduct their own Daubert Analysis [46].

These cross-examination areas include, but are not limited to: whether the psychological methods used have been evaluated in some defensible way. Have the methods been subjected to peer review and accepted within the scientific psychological community? What standard (APA, IACP, POST) has accepted the methods used, and are they appropriately applied to this appellant's case? Is the error rate or confidence level known and reasonable? Is the expert qualified to use the challenged methods (e.g., certain psychological tests)? Has the examiner provided a sufficient basis for the opinions, ratings and recommendations? During cross examination an attorney can raise concerns about a psychologist in four primary areas (e.g., qualifications, bias, culturally responsive substantive points, ethnoracial risk assessment, practice experience and artificial or manufactured issues).First are the area of professional qualifications. Does a psychologist have a documented, historically weak identity with police psychology that is separate (i.e., distinct) from clinical or forensic psychology? For example, is he/she a member of the Society of Police and Criminal Psychology or a member of IACP, Division 18 of APA? Does she/he make a substantial scholarly contribution to the field of police psychology (e.g., refereed publications and conference presentations). Private practice or other work in forensic psychology is insufficient in establishing a police psychology identity in this context [47] Long lists of workshops passively attended over the years are inferior to scholarly work products (e.g., publications or refereed conference presentation on relevant topics).

The second area where a psychological cross-examination can occur is bias. An examiner could be accused of being biased towards a particular appellant. Statements made during the psychological interview, comments in the report, or those made during the hearing itself can be used as a basis for a bias charge. Attorneys may use bias charges as a cross examination strategy [48]. For example, one attorney accused an examiner of not liking an appellant. An appellant's lawyer can even charge that repetitive disqualification opinions by an examiner constitute a bias. For example, a psychologist was accused of bias after twice disqualifying an appellant arrested for soliciting prostitutes in the town where he was applying to be a police officer. Another bias charge was made against a psychologist who disqualified an appellant who had made repeated violent threats against a romantic competitor. The same appellant had been brought before legal authorities twice for the same offense [49]. A cross examination could be focused on any deviation from standard psychological methods. A third cross examination issue is the extent to which, if at all, a psychologist provides a clear statement on the overall risk assessment rating (i.e., supported by documented review) of the applicant's ability to appropriately work with ethnoracial citizens. For example, the high profile deaths on three black males during police contacts and other historically traumatizing cross-racial incidents reinforce the requirement that all psychological examiners carefully explore these negligent hire and retention risk factors in their report [14].

A fourth cross examination issue deals with charges that a psychologist's work in this case is inconsistent with his/her own practice. For example, a department uses the PAI as one of the primary psychological testing tools. The OE psychologist does not use the PAI in his own practice. Moreover, he/she never completed any approved training or received recognized professional supervision in the use of the PAI. When questioned about his training in the use of the PAI in a department that he is testifying against, he/she reports that a colleague provided instruction on the use of the test. On cross examination it was determined that the colleague who supposedly provided the training was a masters-level practitioner who was being supervised by the OE psychologist. In this case, the OE psychologist's practice does not match services he/she is delivering in this appellant's case [50].

\section{Psychological Appeal Hearings and Public Safety Risk Assessment}

The PAH procedures do not absolve participants or their work products (i.e., findings, opinions, reports) from the responsibility to be mindful of the safety sensitive nature of police work. A recommended 
format is, "It is the opinion of this hearing panel (or psychological examiner) that the appellant constitutes a low/medium/or high risk for the police officer position in question." There must also be a separate ethnoracial risk assessment rating. Finally, the end report (hearing officer rulings and various psychological reports) must be signed by all individuals rendering an opinion based on their risk analysis of the appellant. What may be a low or high risk for one person may not be the case for someone else.

\section{Conclusions, Implications for Practice, Research and Training}

All psychologists participating in $\mathrm{PAH}$ must embrace immutable ethical principles (e.g., competence, non-malfeasance). Each examination must capture how that officer perceives different types of an integrity personal corruption (i.e., questionable self-gain or selfsatisfaction) or behavioral judgment that would pose any future problem linked to subsequent misconduct. These are examples of integrity personal corruption that reduce ethnoracial public trust in police or fuel perceptions of illegitimacy of the department. Appellants in a PAH may have unwanted actions, attitudes, judgment lapses, thinking, reasoning), and are more vulnerable to misusing their authority, or to taking undesirable actions for personal gain, which are defensible "rule out" behaviors.

The nature of a police officer's authority, preexisting vulnerabilities, and a full spectrum of duties all merge to create the highest level of occupational stress [10]. Thus, these job-relevant circumstances require the judicious application of higher psychological standards than civilian and military positions require. For example, police officer must be able to demonstrate their ability to maintain trust when working in ethnoracially diverse communities. From a post-Ferguson perspective, the lack of ethnoracial diversity in those individuals performing these forensic psychological evaluations also represents a glaring gap in the culturally responsive credibility of many police departments.

Addressing the clinical forensic and research challenges related to $\mathrm{PAH}$ probably should initially focus on practical problems. The lack of an empirically-based assessment for hearing officer's specific competence in the professions that they are making decisions is a glaring hole in the process. A study is warranted on a thorough credential assessment and two-year recertification reviews for all hearing officers, their psychological expertise, and psychology CEUs. A blind panel psychological review is in order for ratings of their written opinions (strong disagreement, disagreement, agreement, strong agreement) decision from the PAH. For example, to what extent would a written opinion hold up within a psychological framework or paradigm from independent licensed psychologists? [51]. To reduce reflexive skepticism of PAH opinions, research must follow the logic that ethnoracial public trust, perceptions of fairness, and perceptions of legitimacy matters are critical [52].

Hearing officers must be continuously recertified in the professional areas (e.g., occupational health and psychology) in which they are hearing cases. The competing interests of appellants, departments, unions, and political appointments can result in a unbalancing strain that makes simple PAH questions much harder to answer in an unbiased manner. In the end, all outcomes from PAH must be defensible with clear and convincing evidence in fulfillment of laws, sense of ethnoracial justice, psychological evidence, the larger society goals of public safety, and trust.

\section{References}

1. Tanigoshi H, Kontos AP, Remley TP Jr (2008) The effectiveness of individual wellness counseling on the wellness of law enforcement officers. Journal of Counseling and Development: JCD, 86(1), 64-74. Retrieved from Vergés A, Vergés A (2001) Integrating contextual issues in ethical decision making ethics and behavior 20(6): 497-507.

2. Beutler LE, Nussbaum PD, Meredith KE (1988) Changing personality patterns of police officers. Professional psychology: Research and practice 19: 503-507.

3. Corey DM, Honig AL (2008) Police psychology in the 21st century. The Police Chief 75-138.

4. Kim RL (2001) Legitimizing community consent to local policing: The need for democratically negotiated community representation on civilian advisory councils. Harvard civil rights-civil liberties law review, 36: 461-525.

5. Sharp D, Atherton S (2007) To serve and protect: The experiences of policing in the community of young people from Black and other ethnic minority groups. British Journal of Criminology 47: 747-763.

6. Lamboo T, Lasthuizen K, Huberts LWJC (2008) How to encourage ethical behaviour: The impact of police leadership on police officers taking gratuities. Edward Elgar Publishing, Northampton, MA 159-177.

7. Sellbom M, Fischler GL, Ben-Porath YS (2007) Identifying MMPI-2 predictors of police officer integrity and misconduct. Criminal Justice and Behavior 34: 985-1004.

8. Johnson R (2012) Triggering events for decision-making in forensic fitness for duty evaluations of police officers. Paper presented at the Annual Meeting of the Academy of Criminal Justice Science conference. New York, New York.

9. Lowman R (1998) Pre-employment screening for psychopathology: A guide to professional practice. Professional Resource Press.

10. Johnson R (2013) Forensic and cross-culturally responsive assessment using the DSM-5: Just the F.A.C.T.S. Journal of Theory Construction and Testing 3: 40-45.

11. Borrero M (2001) The widening mistrust between youth and police; Families in society: The Journal of Contemporary Human Services 82: 399-408.

12. Carr PJ, Napolitano L, Keating J (2007) We never call the cops and here is why: A qualitative examination of legal cynicism in three Philadelphia neighborhoods. Criminology: An Interdisciplinary Journal, 45: 445-480.

13. Hough M (2012) Researching trust in the police and trust in justice: A UK perspective. Policing \& Society 22: 332-345.

14. Johnson R (2013) Forensic psychological evaluations for behavioral disorders in police officers: Reducing negligent hire and retention risks. In Heflgott, J. (Ed.) Criminal Psychology. Vol. II. Praeger.

15. Johnson R (2013) Using the DSM-5 and ICD-11 in forensic and clinical applications with children across racial and ethnic lines. In Koocher, G. P., Norcross, J.C. \& Greene, B. A. Psychologists' Desk Reference (3rdedn), Oxford University Press: New York.

16. Sollund R (2007) Canteen banter or racism: Is there as relationship between Oslo police's use of derogatory terms and their attitudes and conduct toward ethnic minorities? Journal of Scandinavian Studies in Criminology and Crime Prevention 8: 77-96.

17. Satzewich V, Shaffir W (2011) 'Racism versus professionalism: Claims and counterclaims about racial profiling': Rejoinder. Canadian Journal of Criminology and Criminal Justice 53: 125-131.

18. Huisman K, Martinez J, Wilson C (2005) Training police officers on domestic violence and racism: Challenges and strategies. Violence against Women 11: 792-821.

19. Johnson R (2013) Forensic and cross-culturally responsive assessment using the DSM-5: Just the F.A.C.T.S. Journal of Theory Construction and Testing 3: 40-45.

20. American Psychological Association (APA) (2010) Report of the ethics committee, 2009. American Psychologist 65: 483-492. 
21. Kahn M, Taft G (1983) The application of the standard of care doctrine to psychological testing. Behavioral sciences the law 1: 71-84.

22. Gottschalk P (2011) Management challenges in law enforcement: The case of police misconduct and crime. Academic Journal Academic Journal | International Journal of Law Management 53: 169-181.

23. Robinson DF (2012) Bad footage: Surveillance laws, police misconduct, and the internet. Georgetown Law Journal 100: 1399-1435.

24. Wiens AN, Mueller RM (2009) How to complete and use a psychological evaluation in an ethical manner. In Bucky SF, Callan JE, Stricker G Ethical and legal issues for mental health professionals in forensic settings 51-68. New York, NY, US: Routledge/Taylor \& Francis Group.

25. Decker KP (2006) Introduction to fitness for duty evaluations in law enforcement personnel. In: Decker KP (ed.), Fit, unfit or misfit: How to perform fitness for duty evaluations in law enforcement professionals. Springfield, IL: Charles C. Thomas 3-31.

26. Rostow CD, Davis RD (2004) A handbook for psychological fitness-forduty evaluations in law enforcement. New York, NY: The Haworth Clinical Practice Press.

27. Lowman RL (2012) The scientist-practitioner consulting psychologist. Consulting Psychology Journal: Practice and Research 64: 151-156.

28. Neimeyer GJ, Taylor JM, Cox DR (2012) On hope and possibility: Does continuing professional development contribute to ongoing professional competence? Professional Psychology: Research and Practice 43: 476-486.

29. Smith CZ (1990) Definitions, procedures, and guidelines for expert witnesses. In Meek, C.L. (Ed.) Post-traumatic stress disorder: Assessment, differential diagnosis, and forensic evaluation 167-194.

30. Montgomery LM, Cupit BE, Wimberley TK (1999) Complaints, malpractice, and risk management: Professional issues and personal experiences. Professional Psychology: Research and Practice, 30: 402-410.

31. Chen T, LeBourgeois HW (2006) Malpractice action stemming from court-ordered independent medical examination. Journal of the American Academy of Psychiatry and the Law 34: 563-565.

32. Pomerantz AM (2012) Ethical? Toward whom? American Psychologist 67: 324-325.

33. Rogerson MD, Gottlieb MC, Handelsman MM, Knapp S (2011) Nonrational processes in ethical decision making. American Psychologist 66: 614-623.

34. Barnett JE, Behnke SH, Rosenthal SL, Koocher G (2007) In case of ethical dilemma, break glass: Commentary on ethical decision making in practice. Professional psychology: Research and practice, 38: 7-12.

35. Leffler JM, Jackson Y, West AE, McCarty CA, Atkins MS (2013) Training in evidence-based practice across the professional continuum. Professional Psychology: Research and Practice 44: 20-28.

36. Falzon L, Davidson KW, Bruns D (2010) Evidence searching for evidence-based psychology practice. Professional psychology: Research and practice 41: 550-557.

37. Scurich DA, Krauss N (2013) Risk assessment in the law: Legal admissibility, scientific validity, and some disparities between research and practice. Behavioral Sciences \& the Law 31: 215-229.

38. Rostow CD, Davis RD (2004) A handbook for psychological fitness-forduty evaluations in law enforcement. New York, NY: The Haworth Clinical Practice Press.
39. Johnson R, Johnson RA (2012) Anti-terrorism PTSD homeland security response scenarios for modeling and simulation. Homeland Security Modeling Simulation. The 60th Annual Meeting of the Society for Modeling \& Simulation International. Proceedings of the 2012 Autumn Simulation Conference. San Diego, CA. 1: 1-19.

40. Epstein RA (2013) The perilous position of the rule of law and the administrative state. Harvard Journal of Law Public Policy. Winter 36: 5-19.

41. Pierce PJ, Pierce RJ (2010) Administrative law treatise. Kluwer Law \& Business (5thedn), Aspen Publishers.

42. Borum R, Super J, Rand M (2003) Forensic assessment for high-risk occupations. In: Goldstein, A.M. (Ed.) Handbook of psychology: Forensic psychology 11: 133-147.

43. Neimeyer GJ, Taylor JM, Cox DR (2012) On hope and possibility: Does continuing professional development contribute to ongoing professional competence? Professional Psychology: Research and Practice 43: 476-486.

44. Johnson R, Marek W (2012) Professional and ethical issues in outside forensic psychological evaluations of police officers. Paper presented at the 28th Annual Symposium of the American College of Forensic Psychology. San Francisco, Ca.

45. Pope KS, Butcher JN, Seelen J (2006) Washington, DC, US: American Psychological Association 169-201.

46. Pope KS, Butcher JN, Seelen J (2000) Deposition and cross-examination of the expert witness: 100 basic questions. In: The MMPI, MMPI-2 \& MMPI-A in court: A practical guide for expert witnesses and attorneys (2ndedn), Pope Kenneth S, Butcher James N, Seelen Joyce, Washington, DC, US: American Psychological Association 173-224.

47. Macartney-Filgate MS, Snow WG (1997) The practitioner as expert witness. In D.R. Evans (Ed.), The law, standards of practice, and ethics in the practice of psychology. Toronto, ON, Canada: Emond Montgomery Publications 287-309.

48. Commons ML, Miller PM, Gutheil TG (2004) Expert witness perceptions of bias in experts. Journal of the American Academy of Psychiatry and the Law 32: 70-75.

49. Edens JF, Smith ST, Magyar MS, Mullen K, Pitta A, et al. (2012) "Hired guns," "charlatans," and their "voodoo psychobabble": Case law references to various forms of perceived bias among mental health expert witnesses. Psychological Services 9: 259-271.

50. Soudijn KA, Poortinga YH (2012) Professional ethics and enhancement of competent practice. The Oxford handbook of international psychological ethics. New York, NY, US: Oxford University Press 42-52.

51. Benjamin G, Andrew H, Gollan JK (2003) Evidentiary standards and rules of evidence. In: Family evaluation in custody litigation: reducing risks of ethical infractions and malpractice. Forensic practice guidebook. Washington, DC, US: American Psychological Association 17-28.

52. Armstrong A, Shepherd E, Gudjonsson G, Wolchover D (2006) Witness testimony: Psychological, investigative and evidential perspectives. Heaton. New York, NY, US: Oxford University Press. 